\title{
Completion Time Dynamics Of Doctoral Studies At Makerere University: A Hazard Model Evaluation
}

\author{
Robert Wamala, Makerere University, Uganda \\ Joseph Oonyu, Makerere University, Uganda \\ Bruno Ocaya, Makerere University, Uganda
}

\begin{abstract}
Issues related to attrition and completion time of graduate studies are certainly an internationally challenging and important area of higher education literature. In this paper, completion time dynamics of doctoral studies at Makerere University were investigated based on data extracted for all 295 candidates in the commencement cohorts from 2000 to 2005. The total elapsed time, from first enrollment to submission of a final copy of a thesis, was adopted as a measure of completion time and event history (survival) analysis methodology was applied. Results reveal a median completion time of 5.0 years. Following a Cox model, in a range of candidate, candidature, discipline and institutional variables, the rate of completion was higher for candidates at younger ages during commencement, international students, those registered in science-related disciplines, and those in commencement cohorts from 2000 to 2002. The model correctly identified the order of completion times by about $72 \%$ of the time.
\end{abstract}

Keywords: time-to-completion; higher degree studies; Makerere University

\section{INTRODUCTION}

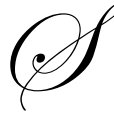

tudent persistence in educational programs is undoubtedly one of the most studied areas in higher education literature. In Canada, UK, USA, and Australia, the concern goes way back to the 1980s for example (Haksever \& Manisali, 2000; Holdaway, 1996; Elgar, 2003; Kerlin, 1995; Lovitts \& Nelson, 2000; Martin, Maclachlan and Karmel, 2001; Smith, Brownell, Simpson \& Deshler, 1993; and Sheridan \& Pyke, 1994). Certainly, the two emerging issues at the forefront of concerns are attrition and completion time of higher degree studies, which are subject to a varying number of characteristics comprising, but not limited to student characteristics (Tinto, 1993; Wright \& Cochrane, 2000; Siegel, 2005; and Vladimir, 2010), field of study (Elger, 2003; Wright \& Cochrane, 2000; and Martin et al, 2001), research facilities and resources (Saint John, Cabrera, Nora \& Asker, 2000; and Tinto, 1993), indirect help, such as outside contacts (Haksever and Manisali, 2000), prior schooling (Wright \& Cochrane, 2000), and supervision and scholarly environment (Ginns, 2004; Harman, 2003; Neumann, 2003; and Leonid \& Mahsood, 2007).

Latone and Browne (2001), in a review of literature on attrition and completion time of higher degree studies, affirm significant association for the variables evaluated following three major categories: 1) institutional factors (including discipline area, candidature characteristics and sense of belonging); 2) supervision arrangements (feedback, meeting frequency, relationships and early start); and 3) candidate characteristics (entry qualifications, nature of enrollment (full-time vs. part-time), and physiological factors.

Despite an abundance of literature on higher degree studies in Europe, America and Asia, equivalent comprehensive studies are not available for African institutions. In Uganda, Mugimu, Nakabugo and Katunguka (2009), as well as Sanders, Guwatudde and Alexander (2008), provide snapshots into the "looming post-graduate crisis" at Makerere University; however, they do not present a statistical assessment of factor impacts examined in 
similar studies conducted in the USA, UK, Canadian, and Australian institutions. Further, Mugimu et al (2009), in their estimation of completion rates, ignore a backlog of graduate students that are still going through the system; thus, compromising the precision of completion statistics reported. Despite the limitations, their presentation is illustrative enough in alerting us to the need for such data and its importance in determining the quality of a program and in attracting students (Gabrielle, 2001; Willging \& Johnson, 2004), as well as growing the number of future academics (Wisdom, 2008).

The literature presented for universities in Europe, America and Asia, despite supporting association of completion time by candidate and candidature characteristics as well as institutional factors, may not precisely explain the situation in Africa's institutions, and particularly in Makerere University. Perhaps, this has to do with differentials in academic cultures and contexts. That notwithstanding, a disparity observed regarding the choice of statistical tools adopted at the univariate, bivariate and multivariate levels of analysis (for example, mean vs. median elapsed time and/or parametric vs. non-parametric methods), presents a challenge in evaluating statistical significance of associations suggested in the results. Further, there are hardly any diagnostic tests presented in quite a number of these studies to affirm the choice of statistical tools adopted in the analysis. In affirming this, Osborne and Elaine (2002) point us to the underreporting of tests on assumptions of statistical tools which researchers rely on when drawing conclusions, thus calling into question the validity of quite a number of results, conclusions and assertions. In any case, the findings provide important insights into information needs for evaluating higher degree studies.

This paper is therefore a result of the need to investigate, from an interactionist point of view, completion time dynamics of doctoral studies at Makerere University. The high level of student enrollment at Makerere, compared to other universities in Uganda, makes it an important context for pursing such an understanding.

\section{DATA AND METHODS}

The duration and completion of doctoral studies can be defined as a form of survival experience, where information on total elapsed time and enrollment status of a candidate (either completed or not) at the time of the survey is known. Thus, methods of event history (survival) analysis were adopted based on institutional data extracted for all 295 doctoral candidates admitted and registered across faculties and/or institutes at Makerere University during the window period 2000 to 2005. The total elapsed time, from first enrollment to submission of a final copy of a thesis, was adopted as a measure of completion time. Virtually, submission of a final copy of a thesis was taken as successful completion of doctoral studies.

The analysis was completed in three stages:

1. A descriptive summary of the duration and probability of completion, which is the survivorship function, is presented following the Kaplan-Meier (1958) estimator.

2. Differentials in survival experiences of candidates across any two or more groups of predictors (candidate characteristics, candidature characteristics and institutional factors, including field of study) were investigated and associations tested using the Log-Rank Chi-square test, together with graphs of survivorship (Mantel, 1966; Peto, 1972).

3. The Cox Proportional Hazard regression (Cox, 1972), a semi-parametric model, was applied in examining the collective net impact of the predictors.

\section{RESULTS OF THE STUDY}

The findings relate to full-time doctoral candidates in Makerere University with the following profile: Predominantly Ugandan by nationality $(94.2 \%)$, registered for thesis-based studies $(81.4 \%)$, male $(76.6 \%)$, married (90.9\%), and solely of Makerere University origin for their Bachelor's and/or Master's Degrees (63.9\%). With regard to age at commencement of doctoral studies, a median of 37 years (ranges 24-61) was realized. Further, slightly over five in every eight doctoral candidates (63\%) were in the commencement cohorts from 2003 to 2005. 


\section{Time-To-Completion Of Doctoral Studies}

From the total enrollment of 295 candidates, 69 had registered 'no load' since their first enrollment in the program, presented by a provisional admission. In other words, their enrollment time was suggested to be zero; thus, they were excluded from the analysis in the subsequent section. Similar to research by Frank (2003) and National Centre for Education Statistics (2003), the study considered such early withdrawals unproblematic ${ }^{1}$.

In view of the fact that the completion time of doctoral studies is not supported on the entire real line $(0, \infty$ ), the assumed normality of the variable is unreasonable. Thus, completion time of doctoral studies - the outcome variable - was subjected to the Shapiro-Wilk test for non-normality (Shapiro and Wilk, 1965). Results of the test, excluding censored observations, provide evidence for the existence of certain types of "non-normality" in the data $(\mathrm{p}<0.01)$. A normality test using the entire dataset $(\mathrm{n}=224)$ reveals similar results. The evidence certainly disqualifies the application of OLS following a linear regression to analyze such data, despite the fact that it can be used to deal with right-censoring - censored normal.

Table 1 presents a descriptive summary of completion time accounting for censored observations, while Table 2 presents the Kaplan-Meier analysis based on a total of 224 doctoral candidates who were confirmed to having registered a load on their candidature at the time of the survey.

Table 1: Descriptive Summary Of Doctoral Completion Time In Months (Years)

\begin{tabular}{|c|c|c|c|c|c|c|}
\hline $\mathbf{N}$ & Min & Max & Median & Std. Error & \multicolumn{2}{|c|}{ 95\% CI [Median] } \\
\cline { 5 - 7 } & & & & & Lower & Upper \\
\hline 89 & $21(1.8)$ & $109(9.1)$ & $60(5.0)$ & 0.77 & $56(4.7)$ & $63(5.3)$ \\
\hline
\end{tabular}

Table 2: Estimated Survivorship Of Doctoral Candidature

\begin{tabular}{|c|c|c|c|c|c|}
\hline Interval [Months] & Enrolled & Completed & Not-Completed & Std. Error & $S(t)^{\mathbf{a}}$ \\
\hline $12-24$ & $224^{\mathrm{b}}$ & 2 & 0 & 0.006 & 0.991 \\
\hline $24-36$ & 222 & 1 & 0 & 0.008 & 0.986 \\
\hline $36-48$ & 221 & 19 & 1 & 0.019 & 0.901 \\
\hline $48-60$ & 201 & 22 & 2 & 0.026 & 0.802 \\
\hline $60-72$ & 177 & 25 & 49 & 0.032 & 0.670 \\
\hline $72-84$ & 103 & 6 & 40 & 0.035 & 0.622 \\
\hline $84-96$ & 57 & 9 & 20 & 0.046 & 0.503 \\
\hline $96-108$ & 28 & 4 & 13 & 0.056 & 0.409 \\
\hline $108-120$ & 11 & 1 & 1 & 0.063 & 0.370 \\
\hline $120-132$ & 9 & 0 & 9 & 0.063 & 0.370 \\
\hline
\end{tabular}

${ }^{\mathrm{a}}$ Survivorship function of doctoral candidature

${ }^{\mathrm{b}}$ Candidates in entering period for 2000 and 2005 who registered a load on their doctoral candidature

By November 2010, a total of 89 (39.7\%) out of the 224 candidates who registered a load on their candidature had completed their doctoral studies. The estimates based on the overall doctoral enrollment at Makerere during the period 2000 to $2005(\mathrm{~N}=295)$ came to $30.1 \%$. According to results in Table 1 , the median completion time of doctoral studies accounting for censored observations was 5.0 years (95\% CI: $4.7-5.3$ ) ranging from 1.8 to 9.1. Further, similar estimates of completion time were realized for thesis-based doctoral candidates. On the other hand, the survival experiences, presented by 12-month intervals in Table 2, point us to low completion levels of doctoral studies in Makerere. Based on a total of 224 candidates, a three-year completion estimate of 1.3\%

\footnotetext{
${ }^{1}$ Frank (2003) and National Centre for Education Statistics (2003) suggest that students who realize their studies may not yield acceptable standards in the institution drop-out and probably transfer to another institution; thus, disregard such early withdrawals to be problematic.
} 
$(n=3)$ was realized, while $19.6 \%(n=44)$ denotes a five-year completion estimate of doctoral studies in the university.

\section{Rate Of Completion Of Doctoral Studies}

The rate of completion of doctoral studies in Makerere was evaluated following a Cox-PH regression; Efron method of handling ties was adopted. The variables included in the final model(s) satisfied a selection criterion - all predictors with probability value (p-value) less than 0.25 during the log-rank tests (age at commencement, sex, type of doctoral registration, nationality, financial assistance and Broad Field of Study). Alternatively, the variables excluded from the final model(s) were marital status and prior schooling (whether candidate was a graduate from within the host university or not), so it is highly unlikely that the predictors will contribute anything to the final model.

The age at commencement of doctoral studies yielded a better overall model fit in the general model (AIC: 816.1 versus 823.7) and thesis-based model (AIC: 720.3 versus 728.6) when evaluated using a categorical outcome. Tables $3 \& 4$ present results of the Cox regression for doctoral studies in general and thesis-based doctoral studies at Makerere University, respectively. The results comprise of Beta coefficients ( $\beta_{x}$ ), hazard ratios and respective $95 \%$ confidence interval (HR: 95\% CI), standard errors of the hazard ratio (Std. Err), and significance levels following the Wald test of the null hypothesis $H_{0}: \beta_{x}=0$.

Table 3: Completion Rate Of Doctoral Studies In General

\begin{tabular}{|c|c|c|c|c|}
\hline Variable $^{\mathrm{a}}$ & Coef. & HR $(95 \% \text { CI })^{b}$ & Std. Err & $\mathbf{p}$ \\
\hline \multicolumn{5}{|l|}{ Age } \\
\hline Above 41 & . & 1 & . & . \\
\hline $31-40$ & 0.696 & $2.02(1.18-3.46)$ & 0.54 & 0.011 \\
\hline 30 and below & 1.386 & $4.07(2.12-7.79)$ & 1.34 & 0.000 \\
\hline \multicolumn{5}{|l|}{ Doctoral registration } \\
\hline Research & . & 1 & . & . \\
\hline Coursework and Research & -0.367 & $0.68(0.30-1.57)$ & 0.290 & 0.379 \\
\hline \multicolumn{5}{|l|}{ Year of enrollment } \\
\hline $2000-2002$ & . & 1 & . & . \\
\hline $2003-2005$ & -0.664 & $0.51(0.31-0.83)$ & 0.555 & 0.008 \\
\hline \multicolumn{5}{|l|}{ Nationality } \\
\hline Ugandan & . & 1 & . & . \\
\hline Non-Ugandan & 1.069 & $2.95(1.31-6.62)$ & 0.711 & 0.009 \\
\hline \multicolumn{5}{|l|}{ Sex } \\
\hline Male & . & 1 & . & . \\
\hline Female & -0.378 & $0.68(0.38-1.20)$ & 0.253 & 0.188 \\
\hline \multicolumn{5}{|l|}{ Financial assistance } \\
\hline No Assistance & . & 1 & . & . \\
\hline Assistance Held & -0.056 & $0.94(0.56-1.58)$ & 0.127 & 0.837 \\
\hline \multicolumn{5}{|l|}{ Broad Field of Study } \\
\hline Science & . & 1 & . & . \\
\hline Arts & -0.675 & $0.51(0.30-0.81)$ & 0.127 & 0.007 \\
\hline
\end{tabular}

Note. LR Chi2 (8) = 46.3, $\mathrm{p}<0.001, \mathrm{n}=218$ and $\mathrm{AIC}=816.1$

${ }^{\mathrm{a}}$ Bold categories represent reference categories adopted

${ }^{\mathrm{b}} \mathrm{HR}(95 \% \mathrm{CI})$ represents Hazard Ratio and corresponding 95\% Confidence Interval 
Table 4: Completion Rate Of Thesis-Based Doctoral Studies

\begin{tabular}{|c|c|c|c|c|}
\hline Variable $^{\mathrm{a}}$ & Coef. & HR $(95 \%$ CI $)$ & Std. Err & $\mathbf{p}$ \\
\hline \multicolumn{5}{|l|}{ Age } \\
\hline Above 41 & . & 1 & . & . \\
\hline $31-40$ & 0.793 & $2.21(1.24-3.93)$ & 0.294 & 0.007 \\
\hline 30 and below & 1.516 & $4.55(2.31-8.95)$ & 0.344 & 0.000 \\
\hline \multicolumn{5}{|c|}{ Year of enrollment } \\
\hline $2000-2002$ & . & 1 & . & . \\
\hline $2003-2005$ & -0.629 & $0.53(0.32-0.87)$ & 0.254 & 0.014 \\
\hline \multicolumn{5}{|l|}{ Nationality } \\
\hline Ugandan & . & 1 & . & . \\
\hline Non-Ugandan & 1.099 & $3.00(1.23-7.07)$ & 0.445 & 0.015 \\
\hline \multicolumn{5}{|l|}{ Sex } \\
\hline Male & . & 1 & . & . \\
\hline Female & -0.238 & $0.78(0.44-1.39)$ & 0.291 & 0.413 \\
\hline \multicolumn{5}{|c|}{ Financial assistance } \\
\hline No Assistance & . & 1 & . & . \\
\hline Assistance Held & -0.04 & $0.96(0.56-1.61)$ & 0.266 & 0.874 \\
\hline \multicolumn{5}{|c|}{ Broad fields of Study } \\
\hline Science & . & 1 & . & . \\
\hline Arts & -0.828 & $0.44(0.25-0.75)$ & 0.271 & 0.003 \\
\hline
\end{tabular}

Note. LR Chi2 (7) $=42.2, \mathrm{p}<0.001, \mathrm{n}=177$ and $\mathrm{AIC}=720.3$

${ }^{\mathrm{a}}$ Bold categories represent reference categories adopted

\section{Regression Diagnostics}

The following diagnostic tests were carried-out:

1. The global and detailed test of proportional assumptions evaluated, based on Schoenfeld and scaled Schoenfeld residuals, support proportionality assumptions of the Cox-PH regression models presented in Tables $3 \& 4(p>0.05)$.

2. The overall model fit was evaluated using Cox-Snell residual (Cox and Snell, 1968). On comparing the jagged line to the reference line $\left(45^{0}\right.$ line) in Figure 1, the final model(s) fit the data relatively well ${ }^{2}$.

3. Results of the specification error in Table 5 show that the Cox-PH models were well specified, as predicted by hat-statistic (_hat: p < 0.05), while results of hat-square statistic (_hatsq) shows that no additional variables were significant $(\mathrm{p}>0.05)$.

4. The predictive power of the model(s) was evaluated using Harrell's C concordance statistics (Harell, Lee and Mark, 1982;1996). Concordance measures show that by using the predictors, the Cox model correctly identifies the order of survival times for pairs of candidates by about $72 \%$ of the time, for model of doctoral studies in general (Harrell's $C=0.715$, Somers' $\mathrm{D}=0.430$ ), and thesis-based doctoral studies (Harrell's C $=0.7171$, Somers' D $=0.434)$.

5. Disproportionate influence of observation (outliers and influential cases) was determined using likelihood displacement values (Collett, 2003). A graph of likelihood displacement (Figure 2) identifies subject 2111 as influential for model of thesis-based doctoral studies and doctoral studies in general. Removal of the subject led to relatively large changes in the values of the log likelihood.

\footnotetext{
${ }^{2}$ Mario et al (2010) argue that, variability about the 45\% line is still expected for well fitting Cox-model, particularly in the righthand tail because of reduced effective sample caused by prior failures and censoring.
} 


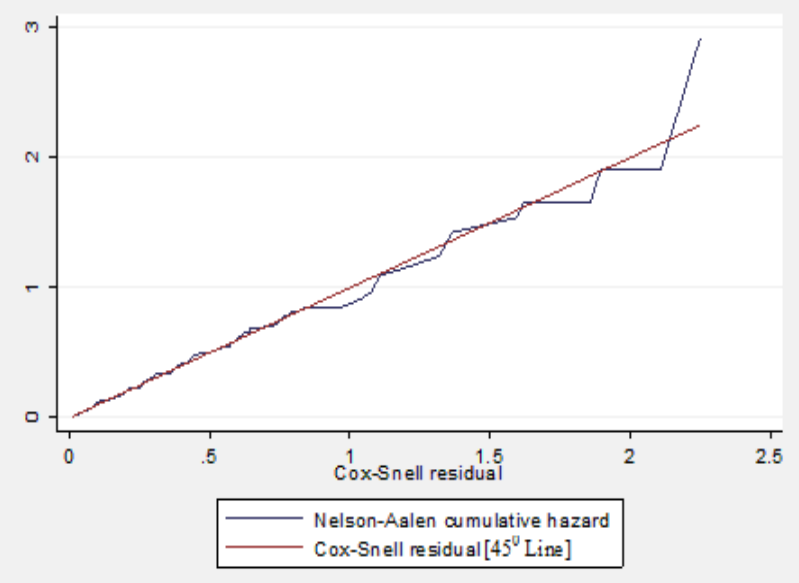

Thesis-based Doctoral Candidates

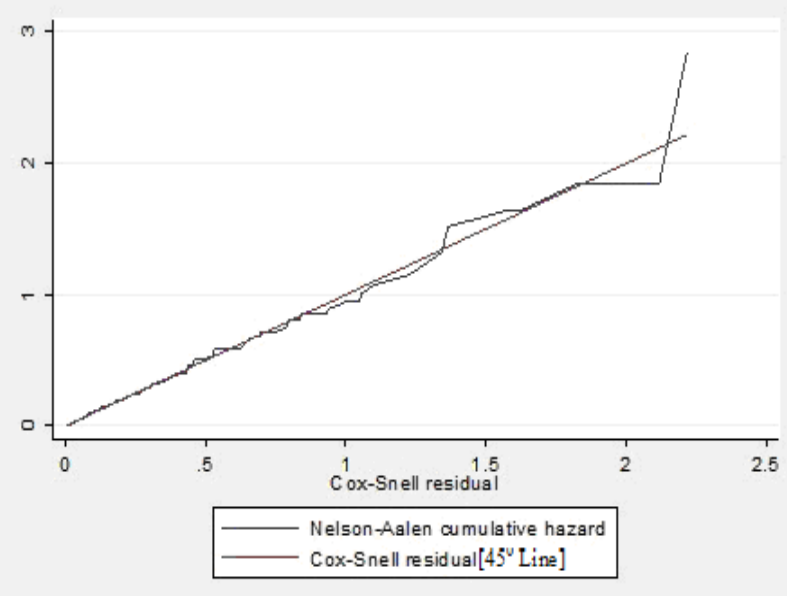

Doctoral Candidates

Figure 1: Cumulative Hazard Of Cox-Snell Residuals

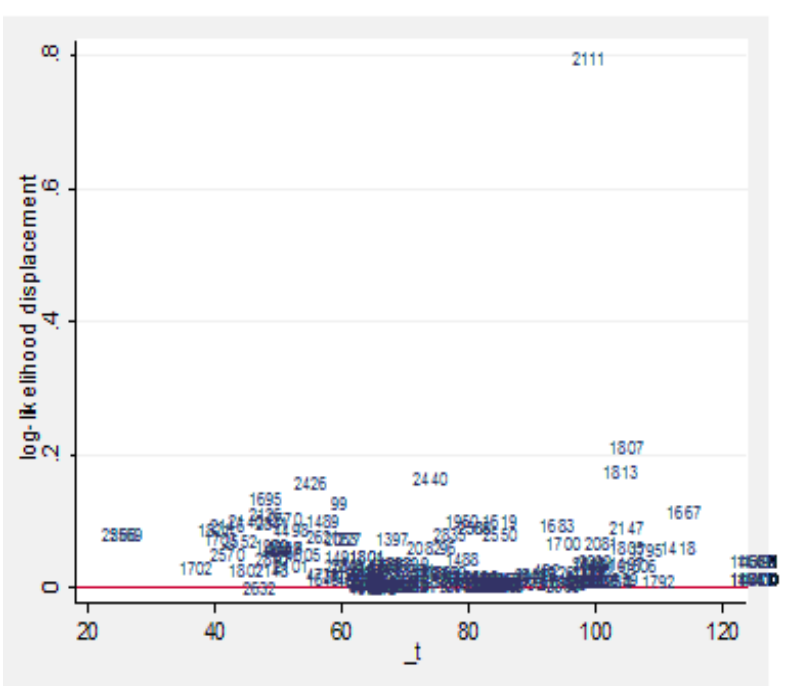

Thesis-based Doctoral Candidates

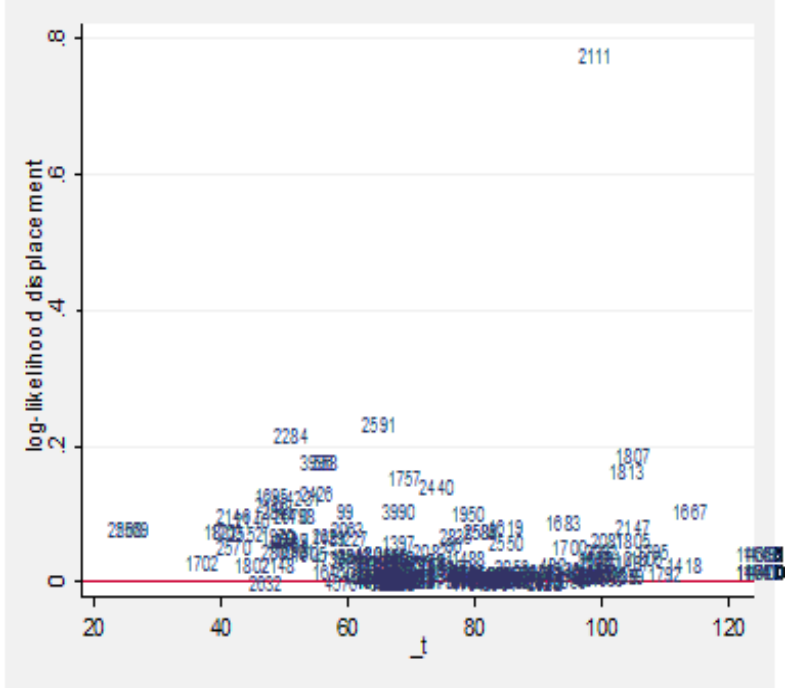

Doctoral Candidates

Figure 2: Likelihood Displacement Values For Model Of Doctoral Studies In General And Thesis-Based Doctoral Studies 
Table 5: Specification Errors Of Link Function

\begin{tabular}{|l|l|l|l|}
\hline Variable & Coef. & Std. Err & p \\
\hline Doctoral Studies & & & \\
\hline hat & 0.967 & 0.146 & 0.000 \\
\hline _hatsq & 0.135 & 0.033 & 0.349 \\
\hline Thesis-based Doctoral Studies & & & \\
\hline hat & 0.903 & 0.172 & 0.000 \\
\hline hhatsq & 0.162 & 0.154 & 0.292 \\
\hline
\end{tabular}

\section{SUMMARY OF THE FINDINGS}

In a general model of doctoral studies of Makerere University (presented in Table 3), significant association with the hazard of completion was noted for the variables; namely, age at commencement, field of study, nationality, and year of enrollment $(\mathrm{p}<0.05)$. In other words:

- The rate of completion was 4.1 times higher among candidates below 30 years and 2.0 times higher among candidates in the age range of 30-40, compared to candidates over 40 at commencement.

- Doctoral candidates enrolled in the arts-related disciplines had a 49\% reduced rate of completion compared to their counterparts in the science-related disciplines (Haz.Ratio $=0.51)$.

- The rate of completion among international candidates was 2.95 times higher than their native counterparts $($ Haz.Ratio $=2.95)$.

- Doctoral candidates in the commencement cohorts from 2003 to 2005 had a $49 \%$ reduced rate of completion compared to candidates enrolled in the period from 2000 to 2002 (Haz.Ratio $=0.51$ ).

- $\quad$ Alternatively, the rate of completion of doctoral studies of Makerere University, in general, did not vary significantly by financial assistance, type of doctoral registration (research vs. coursework and research) and sex of the candidate.

Secondly, in evaluating the rate of completion of thesis-based doctoral studies in Makerere, age at commencement, field of study, nationality, and year of enrollment $(\mathrm{p}<0.05)$ yielded a significant association with the hazard of completion. In other words:

- $\quad$ The rate of completion was 4.5 times higher among candidates younger than 30 years and 2.2 times higher among candidates in the age range of 30-40, compared to candidates over 40 at commencement.

- $\quad$ Thesis-based candidates enrolled in arts-related disciplines had a 56\% reduced rate of completion compared to candidates in the science-related disciplines (Haz.Ratio $=0.44$ ).

- The rate of completion among international candidates was three times higher than their native thesis-based doctoral counterparts (Haz.Ratio $=3.0)$.

- $\quad$ Thesis-based doctoral candidates in the commencement cohorts from 2003 to 2005 had a $47 \%$ reduced rate of completion compared to candidates in the period from 2000 to 2002 (Haz.Ratio $=0.53$ ).

- $\quad$ Alternatively, the rate of completion of thesis-based doctoral studies in Makerere University did not vary significantly by financial assistance and sex of the candidate. 


\section{DISCUSSIONS AND CONCLUSIONS}

The doctoral completion time estimate of Makerere (5.0 years), despite being equal to the maximum permissible period of doctoral candidature in the University ${ }^{3}$, is significantly higher than estimates presented in the literature for selected international universities (for example, Ismail and Abiddin, 2009, in their Malaysian study, report a duration of 4.5 years; Bourke et al, 2004, report a median elapsed duration of 4.4 years at one Australian University). Worth noting is the dearth of documented evidence regarding completion estimates of doctoral studies among universities in Africa, thus making comparisons impossible. Nevertheless, the completion time (5.0 years) and completion $(30.1 \%)$ statistics generated suggest a low turnout of doctoral students at the university.

Following Tinto's $(1975 ; 1993)$ interactionist point of view, quite a number of associations were supported in the analysis. With regard to candidate demographics, the results corroborate literature that has established differentials in completion time by age at commencement of doctoral studies (for example, Bourke, Holbrook \& Lovat, 2004; Martin et al, 2001) and nationality (Bourke et al, 2004; Sheridan \& Pyke, 1994; Wright \& Cochrane, 2000). However, the findings run counter to literature that has established differentials in completion time of doctoral studies by gender (for example, Council of Graduate School, 2008; D'Andrea, 2002; Siegel, 2005), marital status, prior schooling (Wright \& Cochrane, 2000), and type of doctoral registration (Smith, 1993). Unlike Bourke and Martin who identified timely completers among doctoral candidates at the older ages, timely completers in this study were noted to be candidates at the younger ages of commencement. Worth mentioning, the median age at commencement of doctoral studies in Makerere (37 years), though being lower than the maximum permissible in the university ${ }^{4}$, is rather high. As a matter of fact, doctoral studies in the university are characterized by adult learners who may not only be faced with family and financial concerns (Ely, 1997), but also oftentimes ill-prepared to deal with the challenges that graduate studies pose to them (Lovitts, 2005). Thus, the need for appropriate remedial programs to address academic unpreparedness of such students is a necessity. With regard to nationality, the consensus is that timely completers are noted among international doctoral candidates.

In the same vein, the results add to literature that has established a significant association between completion time of doctoral studies and field of study (Bourke et al, 2004; Martin et al, 2001; Mugimu et al, 2009; Wright \& Cochrane, 2000; Vladimir, 2010). The consensus is that a shorter completion time of doctoral studies is noted among candidates enrolled in science-related disciplines. In an attempt to provide an explanation for the discipline differential in regard to completion time of higher degree studies in Makerere, following the student perspective approach, research by Mugimu et al (2009) points us to academic isolation of students and staff, particularly in the arts-based disciplines. Perhaps this is due to the high enrollment of students in the Arts discipline compared to science-related disciplines, thus resulting in a heavy teaching, supervisory and administrative workload. No wonder the arts-related disciplines are characterized with more backlog of graduate students. In any case, the need to promote activities that enhance students' free interaction with fellow peers and academic staff will certainly go a long way in building a higher turnout of graduate students in Makerere (Mendoza, 2007; Mugimu et al, 2009).

The hypothesis of timely completion of doctoral candidates with financial assistance was not supported. In other words, the findings run counter to research that has identified timely completers to be doctoral candidates with financial assistance (Ismail \& Abiddin, 2009; Mugimu et al, 2009; Saint John, 2000; Tinto, 1993; Valentine, 1997). In a recent research, following the student perspective, Mugimu et al (2009) identified financial assistance as a key influencing factor for and/or against timely completion of graduate studies in Makerere University. However, the results adopting the institutional perspective did not provide statistical evidence to support the hypothesis. Nevertheless, in addition to increased financial assistance required for doctoral studies in Makerere, the study recommends stepping-up of measures to ensure time-bound nature of financial assistance with stringent measures on extensions.

\footnotetext{
${ }^{3}$ Reference is made to the requirements of academic training in Makerere University Human Resource Manual (2009), which specifies minimum and maximum periods of doctoral candidature to be 3 and 5 years, respectively.

${ }^{4}$ The eligibility requirements of academic training in Makerere University Human Resource Manual (2009) specifies the ages 45 and 40 as maximum permissible at commencement of doctoral studies for females and males, respectively.
} 
Worth mentioning is the reduced rate of completion of doctoral studies of candidates in the commencement cohorts from 2003 to 2005 compared to their counterparts in earlier years. The findings support assertions of an increase in completion time of doctoral studies of Makerere University "in recent years". In a review of graduate students' perceptions of support needed for timely completion of their studies in Makerere University, supervisory and administrative-related requirements were ranked highest (Mugimu et al, 2009). Particularly, the administrative support requirements comprised, however not limited to, timely approval of viva and students' work, maintaining proper records and establishing students' support committees.

In view of the fact that a number of associations with the variables were supported in the results, the dynamics of doctoral completion time at Makerere is clearly not an isolated case of graduate studies, but relates favorably with experiences reported among international universities. However, this may not be the case with the contextual issues surrounding these associations.

\section{AUTHOR INFORMATION}

Robert Wamala, MDMG: Holds a Bachelor of Statistics and Master's of Arts Degree in Demography of Makerere University; and, currently an advanced Ph.D candidate (Statistics) at the School of Statistics and Applied Economics (SSAE), Makerere University located in Kampala the capital city of Uganda. A specialist in quantitative data, analysis methodology and related statistical software applications including the following: STATA, SPSS, ENPIIFO, EPIDATA, CSPRO, MINITAB, EVIEWS. I have worked with the School of Statistics and Applied Economics, Makerere University since 2004 and handle data and related aspects of quantitative research methodology. Email: rwamala@isae.mak.ac.ug

Joseph C. Oonyu, Ph.D: Senior Lecturer, Department of Science and Technical Education, and currently the Deputy Dean, School of Education, College of Education and External Studies, Makerere University. Dr. Oonyu's educational background is the biological sciences where he graduated with a B.Sc. (Hons) degree. He holds a M.Sc. degree in Zoology and a PhD in Science Education (University of Alberta/Makerere University. Dr. Oonyu also holds a Diploma in Education, and a Post Graduate Diploma in Higher education Studies. Email: joonyu@educ.mak.ac.ug

Ocaya Bruno, PhD: Studied economics, majoring in econometrics from Northwestern University, Evanston, Ill, USA; a Masters' degree from Latrobe University, Melbourne, Australia; and a First Class Bachelors' degree in economics from Makerere University, Uganda. He has a diverse and long teaching carrier in various fields of economics at different levels in the respective universities he graduated from. Africa's most reputed economics programme. Currently, teaches and supervises graduate students pursuing masters and $\mathrm{PhD}$ in statistics and quantitative economics at Makerere University. Email: bocaya@isae.mak.ac.ug

\section{REFERENCES}

1. Bourke, S., Holbrook, A. \& Lovat, T. (2004). Relationships of PhD candidate, candidature and examination characteristics with thesis outcomes. The AARE Annual Conference, Adelaide, Australia.

2. Cox, D. R. and Oakes, D. (1984). Analysis of Survival Data. London: Chapman and Hall.

3. D'Andrea, L. M. (2002). Obstacles to completion of the doctoral degree in colleges of education. Educational Research Quarterly.

4. Ely, E. E. (1997). The non-traditional student. American Association of Community Colleges Annual Conference. Anaheim, CA, April 12-15. (JC970516)

5. Harman, G. (2003). PhD student satisfaction with course experience and supervision in two Australian research-intensive universities. Prometheus, 21(3), 317-333.

6. Haksever, A. M. and Manisali, E. (2000). Assessing supervision requirements of PhD students: The case of construction management and engineering in the UK. European Journal of Engineering Education, March, $1-8$.

7. Ismail, A. and Abidin, N. Z. (2009). Service attributes of Graduate Research Students' needs in a Malaysian University. The Journal of International Social Research, 2(6), 1-2 
8. Latona, K. \& Browne, M. (2001). Factors Associated with Completion of Research Higher Degrees. Higher Education Series, Report No.37, May, Higher Education Division, Department of Education, Training and Youth Affairs, Canberra.

9. Leonid Grebennikov and Mahsood Shah (2007). Enhancing the Research student Experience at University, University of Western Sydney. Australasian Association for Institutional Research Forum

10. Lovitts, B. E. \& Nelson, C. (2000). The Hidden Crisis in Graduate Education: Attrition from PhD Programs. Academe, 86(6), 44-50.

11. Martin, Y. M., Maclachlan, M. \& Karmel, T. (2001). Postgraduate Completion Rates. Occasional Paper Series, Higher Education Division, DETYA (now DEST), Canberra.

12. Mantel, N. (1966). Evaluation of survival data and two new rank order statistics arising in its consideration. Cancer Chemotherapy Reports, 50 (3), 163-70.

13. Mario, Cleves, Roberto G. Gutierrez, William Gould and Yulia, V. Marchenko (2010). An introduction to Survival Analysis Using Stata ( $3^{\text {rd }}$ ed). StataCorp LP

14. Mugimu Christopher B., Nakabugo Mary G. and Katunguka R. Eli (2009). Exploring Factors affecting Staff Research output and Completion Rates of Graduate Students in Makerere University. Unpub. Report

15. Saint John, E., Cabrera, A., Nora, A. and Asker, E. (2000). Economic influences on persistence reconsidered: How can finance research inform the reconceptualization of persistence models.

16. Sanders, D., Guwatudde, D. \& Alexander, L. (2008). Accessible public-health education: a potential growth area. Bull World Health Organization. 86(8), PMID: 0042-9686

17. Smith, S. W., Brownell, M. T., Simpson, R.L. \& Deshler, D.D. (1993). Successfully Completing the Dissertation: Two Reflections on the Process. Remedial and Special Education, 14(3), 53-60.

18. Tinto, V. (1993). Leaving College: Rethinking the causes and cures of student attrition. (2 ${ }^{\text {nd }}$ ed.). Chicago: University of Chicago Press.

19. Vladimir Jiranek (2010). Potential Predictors of Timely Completion among Dissertation Research Students at an Australian Faculty of Sciences. International Journal of Doctoral Studies.

20. Wisdom Tetty (2008). Comparative Analysis of Next Generation of Academics Indicators. The University Leaders' Forum. Accra, Ghana

21. Wright, T., \& Cochrane, R. (2000). Factors influencing successful submission of PhD Theses. Studies in Higher Education, 25, 181-195. 